\title{
UJI AKTIVITAS INSEKTISIDA BEBERAPA EKSTRAK TANAMAN PADA HAM A LIRIOMYZA SATIVAE (BLANCHARD)
}

\author{
Karolus A.N. Nainiti ${ }^{11}, 1$ Wayan Supartha ${ }^{21}$ dan IG.M.Oka Nurjaya ${ }^{21}$ \\ 1 )FakuItas Pertanian Universitas Flores, 2) Pascasarjana Pertanian lahan kering Udayana \\ karolus_nainiti@yahoo.com
}

\begin{abstract}
The Experiment Insecticide Activity of Plant Extracts on Liriomyza sativae (BLANCHARD)

The usage of herbal insecticide for leafminer control are based on the principle that organic compounds that are produced by plants to survive from the leafminer are selective, can be digested by organism, and also can be brokendown by heat, oxygen, and sunshine. This study was to test activity of 15 plant extracts to find out which kinds of plant extracts had insecticide activity to Liriomyza sativae. The study design was randomized block design, with 17 treatments (15 kinds of plant extract and two controls), and was replicated five times. The trials were done at the glasshouse of Pest and Plant Disease Department of Agricultural Faculty at Udayana University. The results of the study showed that each plant extract that were used in these trial had different insecticide activity to $L$ sativae. The seed coat extract from the seed $A$. occidentale $\mathrm{L}$. and the extract of $P$. retrofractum Vahl had the highest insecticide activity to $L$ sativae.
\end{abstract}

Keywords: Herbal insecticide, Liriomyza sativae, Anacardium occidentale L. and Piper retrofractum Vahl.

\section{PENDAHULUAN}

Salah satu hama yang perlu diwaspadai keberadaannya adalah hama Liriomyza spp. (Diptera: Agromyzidae). Menurut Cardona dan Karel, 1990; Supartha, 1998a, serangan hama Liriomyza spp. pada daun dapat menyebabkan terganggunya proses fotosintetis dan respirasi tanaman karena tusukan ovipositor imago untuk keperluan makan dan bertelur serta korokan larva Liriomyza spp. pada jaringan mesofil daun mengurangi luas permukaan daun. Pada serangan berat akan menyebabkan daun gugur sebelum waktunya.

Hama Liriomyza spp. dikenal sebagai lalat pengorok daun (leafminer fly), termasuk ordo Diptera, famili Agromyzidae, subfamili Phitomyzinae. Subfamili Phitomyzinae terdiri dari beberapa genus, dan semuanya merupakan hama tanaman sayuran. Liriomyza adalah salah satu genus dari famili Phitomyzinae yang memiliki beberapa spesies antara lain Liriomyza sativae, L Imidobrensis, L trifolii, L. chinensis, L bryoninae (Raman. 1988).

Kisaran tanaman inang Liriomyza spp. luas seperti tanaman kentang, kubis, seledri, bawang, bayam, buncis, kacang panjang, kacang merah, brokoli, selada, wortel, kangkung, mentimun, melon, cabai, tomat, caisin, waluh dan beberapa jenis tanaman hias seperti krisan dan dahlia serta gulma yang satu famili dengan tanaman pertanian yang menjadi tanaman inang (Rauf et $\ll ., 2000)$.
Pendekatan pengendalian Liriomyza spp. yang disarankan oleh pemerintah melalui Dinas Pertanian adalah pengendalian hama terpadu (PHT) seperti rotasi tanaman, penggunaan variatas tahan, penyiangan, memusnahkan daun yang terserang, penggunaan mulsa plastik, pemanfaatan musuh alami, penggunaan insektisida nabati dan sintetis.

Upaya pengendalian Liriomyza spp. yang dilakukan petani hanya bertumpu pada penggunaan insektisida sintetis, karena praktis dan berdasarkan pengalaman insektisida sinstetis paling efektif dalam mengendalikan hama.

Harwanto dkk., (2001) melaporkan bahwa pengendalian L. Imidobrensis di Desa Sukama, Pengalengan, Propinsi Jawa Barat menggunakan insektisida sintetis karbosulfan secara konvensional pada konsentrasi 1,5\% dengan frekuensi aplikasi satu kali per minggu menyebabkan meningkatnya populasi $L$ Imidobrensis pada interval waktu 54 hari setelah tanam dan jumlah populasi tertinggi terjadi pada 68 hari setelah tanam yaitu 14 ekor $L$ Imidobrensis pada setiap tiga tanaman kentang. Diduga pengendalian -dengan insektisida karbosulfan merangsang reproduksi, resurjensi dan resistensi L. Huidobrensis, juga karena terjadinya penurunan populasi predator Coenosia luunilis Meigan (Diptera: Muscidae), dan musuh alami lain yang tidak teridentifikasi sebelumnya.

Pemanfaatan insektisida nabati untuk pengendalian hama Liriomyza spp. sangat potensial, selain karena murah juga aman bagi lingkungan karena senyawa-senyawa organik 
yang dihasilkan oleh tanaman untuk mempertahankan diri dari organisme pengganggu bersifat selektif, bisa dicerna oleh organisme, dan dapat mengalami pemecahan (breakdown) oleh panas, oksigen dan sinar matahari.

Ekstrak daun mimba (Azadirachta inclica A.Juss.) dilaporkan sangat et'ektif sebagai penghambat makan (antifeedant/feeding deterrent) terhadap L. trifolii (Fagoonee dan Torry 1984 dalam Minkenberg dan Van Lenteren 1986). Ekstrak biji mimba dapat berperan sebagai penolak/penghambat peneluran (oviposition repellent/deterrent) dan racun perut yang menyebabkan kematian $100 \%$ larva $L$. trifolii dan $98 \%$ pada $L$. sativae (Webb dkk., 1983).

Ada beberapa jenis tanaman sumber bahan aktif insektisida nabati selain tanaman mimba yang sering digunakan petani di desa Baumata dan Kuaklalo kecamatan Kupang Tengah kabupaten Kupang Propinsi Nusa Tenggara Timur (NTT) sebagai sumber bahan aktif insektisida nabati (Tabel !.)• Informasi tentang aktivitas insektisida dari ekstrak jenis tanamantanaman tersebut terhadap $L$. sativae belum diketahui. (wawancara dengan tokoh-tokoh adat di Desa Oehani dan Baumata Kecamatan Kupang Tengah Kabupaten Kupang-NTT, 2005), oleh karena itu penelitian ini dilakukan. Tujuan penelitian ini adalah untuk mengetahui ekstrak tanaman mana yang mempunyai aktifitas insektisida paling tinggi terhadap L. sativae.

\section{BAHAN DAN METODE}

Bahan yang digunakan adalah bibit kacang merah (Vigna sinensis (L.) Hassk.), L. sativa, tanah, pupuk kompos, methanol, aquades. bahan kering 15 tanaman (Tabel 1.). Alat yang akan digunakan dalam penelitian ini tahap satu adalah pisau, polybag, sprayer, gelas ukur, tabung reaksi, stoples plastik bening, kurungan pembiakan, kurungan percobaan, stoples penetasan, kertas sating Whatman no.2, Vaccuin rotary evaporator, kaca pembesar, pipet, blender, kain kasa, penggaris, pensil. bolpoin, spidol, kertas label, kertas milimter blok, dan lembar pengamatan.

Tempat pelaksanaan percobaan di Rumah kaca milik Jurusan Hama dan Penyakit Tumbuhan Fakultas Pertanian UNUD. Rancangan percobaan yang digunakan adalah rancangan acak kelompok (RAK), dengan satu faktor (15 ekstrak tanaman ditambah dua kontrol: methanol dan aquades, sehingga menjadi 17 perlakuan), diulang lima kali sehingga terdapat 85 unit percobaan. Kontrol aquades yang dijadikan acuan pada uji beda. Dilakukan pengelompokan menurut hari karena unit percobaan banyak. Variabel yang diamati adalah : (1) aktivitas racun kontak, (2) aktivitas repellen, (3) aktivitas antifidan dan (4) aktivitas racun perut.

Tabel 1. Nama tanaman-tanaman yang ekstraknya dipakai untuk percobaan

\begin{tabular}{clll}
\hline No & Nama umum/lokal & \multicolumn{1}{c}{ Nama Biologi } & Bagian yang digunakan \\
\hline 1 & Sirsak & Annona muricata L. & Daun \\
2 & Kelapa & Cocos mtcifera & Daging buah \\
3 & Manusfui & Piper retrofractiim Vahl. & Buah \\
4 & Belbelu/Kixyu ular & Stryclwos ligitstrina & Kulit batang \\
5 & Jambu mente & Anacardiuni occidentale L. & Kulit biji \\
6 & Kelor & Molinga oleifera & Kulit batang \\
7 & N/l.7.y/Trengguli & Casia fistula L. & Kulit batang \\
8 & Tuiunolo & Thevetia perviana L. & Bunga \\
9 & Mad & Amorphophalluss variabilis & Umbi \\
10 & Anonak & Annona squamosa L. & Kulit batang \\
11 & Nengkai & Acassia spp. & Kulit batang \\
12 & Koto Fiti & Mucnna pruriensvar utilis & Biji \\
13 & Legundi & Vitex trifolia & Daun \\
14 & Mengkudu & Morinda citrqfila & Kulit akar \\
15 & Let el & Astonia scholaris & Kulit batang \\
\hline
\end{tabular}

Metode uji aktivitas racun kontak menurut Prijono,1988 dapat dilakukan dengan metode residu yaitu ekstrak kasar dalam bentuk larutan disemprotkan secara merata ke seliiruh permukaan bagian dalam toples dan selama 30 menit dikering anginkan agar pelarut insektisida menguap. Toples yang digunakan berdiameter $15 \mathrm{~cm}$ dan tinggi $10 \mathrm{~cm}$. Dosis insektisida yang digunakan sebanyak 0,5 $\mathrm{ml}$ untuk setiap toples dengan konsentrasi sesuai perlakuan. Ke dalam toples yang pelarutnya telah kering dilepaskan 10 imago L. sativae (umur 4 hari) Pengamatan aktivitas racun kontak dilakukan selama 720 menit (12 jam). Interval waktu pengamatannya adalah 5 menit; 15 menit; 30 menit; 60 menit;120 menit; 240 menit; 360 menit; 480 menit; 600 menit dan 
720 menit. Aktivitas racun kontak menurut Prijono (1988), dapat lihat dari kematian serangga karena pengaruh perlakuan, yang

$$
\mathrm{KS}=\left(; \frac{\text { Msp }}{\mathrm{Pla}}\right) \times 100 \% \text {. }
$$

dinyatakan dalam persentase dan ditentukan dengan menggunakan rumus :

Keteran»an :

$$
\begin{aligned}
& \mathrm{KS}=\text { Kematian } L \text { sativae }(\%) \\
& \mathrm{Msp}=\text { Kematian } L . \text { sativae } \text { setelah perlakuan } \\
& \text { Psa }=\text { Populasi } L . \text { sativae } \text { awal }
\end{aligned}
$$

Metode uji aktivitas repellen dilakukan dengan metode "Leaf Disk" yaitu menggunakan tanaman dengan jumlah daun yang sama (Prijono,1988). Pada percobaan ini tanaman yang digunakan adalah kacang merah yang telah berumur 12 hari, jumlah daun tanaman kacang merah yang digunakan sebanyak dua daun (daun pertama). Kedua permukaan daun (atas dan bawah) dilapisi ekstrak kasar dengan cara disemprot. Dosis yang digunakan $0,3 \mathrm{ml}$ per tanaman, pada konsentrasi sesuai perlakuan. Daun tanaman yang telah disemprot dibiarkan selama 15 menit agar pelarutnya menguap. Setiap tanaman yang telah diberi perlakuan dimasukkan dalam toples yang berdiameter $20 \mathrm{~cm}$ dan tint; «i

$$
\mathrm{PK}=\left(\frac{\mathrm{Kpp}}{\mathrm{Kpk}}\right) \times 100 \%
$$

Keteran«an :

$$
\begin{aligned}
& \mathrm{PK}=\text { Penurunan Kunjungan }(\%) \\
& \mathrm{Kpp}=\text { Jumlah } L \text { sativae yang berkunjung pada perlakuan } \\
& \text { Kpk = Jumlah L. sativae yang berkunjung pada kontrol }
\end{aligned}
$$

$45 \mathrm{~cm}$. Ke dalam tiap toples yang berisi satu tanaman kacang merah yang telah diberi perlakuan insektisida dimasukkan 5 imago $L$. sativae (umur 4 hari). Pengamatan dilakukan untuk mengamati ada atau tidak adanya kunjungan $L$. sativae pada tanaman yang telah diberi perlakuan. Lama dan interval waktu pengamatan aktivitas repellen sama dengan lama dan interval waktu pengamatan pada uji aktivitas racun kontak. Aktivitas repellen menurut Prijono (1988), dapat lihat dari jumlah penurunan kunjungan serangga karena pengaruh perlakuan, yang dinyatakan dalam persentase dan ditentukan dengan menggunakan rumus :
Metode uji aktivitas antifidan sama dengan metode uji aktivitas insektisida repellen. Bedanya adalah pengamatan dilakukan setelah 720 menit (12 jam) untuk mengetahui ada atau tidak adanya penurunan aktivitas makan L. sativae Aktivitas antifidan. Aktifitas makan

$$
\mathrm{PM}=\left(\frac{\mathrm{Jtp}}{\mathrm{Jtk}}\right) \times 100 \%
$$

diketahui dari ada dan banyaknya tusukan pada daun tanaman. menurut Prijono (1988), dapat lihat dari jumlah penurunan aktivitas makan serangga karena pengaruh perlakuan, yang dinyatakan dalam persentase dan ditentukan dengan menggunakan rumus :

Keterangan :

$$
\begin{aligned}
& \mathrm{PM}=\text { Penurunan aktivitas makan } L \text {. sativae }(\%) \\
& \mathrm{Jtp}=\text { Jumlah tusukan } L \text { sativae pada daun perlakuan } \\
& \mathrm{Jtk}=\text { Jumlah tusukan } L \text { sativae pada daun kontrol }
\end{aligned}
$$

Metode uji aktivitas insektisida racun perut sama dengan metode uji aktivitas insektisida repellen (4.1.5.2). Bedanya adalah pengamatan dilakukan untuk mengamati kematian imago $L$ sativae setelah 720 menit (12 jam). Aktivitas racun perut menurut Prijono (1988), dapat lihat

$$
\mathrm{PM}=\left(\frac{\mathrm{Msp}}{\mathrm{Pla}}\right) \times 100 \%
$$

dari peningkatan kematian serangga setelah makan dari tanaman perlakuan, yang dinyatakan dalam persentase dan ditentukan dengan menggunakan rumus :

Keterangan : 
$\mathrm{PM}=$ Peningkatan kematian L. sativae (\%)

Msp = Kematian L. sativae setelah perlakuan

Pla = Populasi L. sativae awal

Data yang terkumpul sebelum dianalisis ditransformasi dengan transformasi arcsin (Vpersentase). Untuk melihat tingkat nyata pengaruh perlakuan digunakan analisis siclik ragam. Sedangkan untuk mengetahui perbedaan kemampaun aktivitas insektisida dari antara ekstrak tanaman terhadap imago Liriomyza spp. akan dilanjutkan dengan Duncan's Multiple Range Test (Steel dan Torrie, 1980).

\section{HASIL DAN PEMBAHASAN}

Hasil analisis sidik ragam menunjukkan bahwa uji aktivitas insektisida ekstrak beberapa tanaman berpengaruh sangat nyata terhadap $L$. sativae. pada semua variabel pengamatan.

Aktivitas racun kontak. Pada pengujian aktivitas insektisida racun kontak perlakuan ekstrak kulit biji tanaman A. occidentale L. menunjukkan rata-rata persentase kematian imago L. sativae tertinggi, yang berbeda sangat nyata dengan kontrol dan perlakuan ekstrak tanaman lainnya ( Tabel 2.).

Aktivitas repellen. Rendahnya kunjungan imago L. sativae pada tanaman inang dengan perlakuan ekstrak kulit biji tanaman $A$. occidentale L. tidak dapat dipastikan sebagai akibat aktivitas repellen karena adanya kerusakan daun. Aplikasi ekstrak buah tanaman $P$. retrofractum Vahl. menyebabkan kunjungan imago L. sativae pada tanaman inang terendah kedua, yang berbeda nyata dengan kontrol dan perlakuan lainnya (Tabel 3.).

Aktivitas antifidan. Aktivitas makan L. sativae pada perlakuan aplikasi ekstrak kulit biji tanaman A. occidentale L. tidak dapat diamati karena menyebabkan kerusakan seluruh permukaan daun. Aplikasi ekstrak buah tanaman $P$. retrofractum Vahl. pada tanaman inang menunjukkan rata-rata aktivitas makan L. sativae terendah, yang berbedanyata dengan kontrol tetapi berbeda tidak nyata dengan rata-rata aktivitas makan $L$. sativae yang disebabkan oleh ekstrak daging buah tanaman C. nucifera, ekstrak kulit batang $S$. ligustrina, ekstrak kulit batang tanaman C. fistula L. (Tabel 3.).

Aktivitas racun perut. Tidak dapat dipastikan adanya aktivitas makan, menyebabkan rata-rata kematian tertinggi imago L. sativae pada perlakuan ekstrak kulit biji tanaman $A$. occidentale L. juga tidak dapat dipastikan sebagai pengaruh aktivitas racun perut. Rata-rata kematian imago tertinggi kedua ditunjukkan oleh perlakuan ekstrak buah tanaman $P$. retrofractum Vahl., yang berbeda tidak nyata dengan perlakuan ekstrak daging buah tanaman $C$. nucifera, ekstrak bunga tanaman T. perviana L., ekstrak kulit batang tanaman Acassia spp. dan berbeda nyata dengan kontrol dan perlakuan lainnya (Tabel 3.).

Tabel 2. Rerata persentase kemataian imago L. Sativae karena ktivitas racun kontak dari setiap ekstrak tanaman

\begin{tabular}{ll}
\hline Perlakuan & Kematian imago (\%) \\
\hline Annona inuricata L. & $58,00 \mathrm{~cd}$ \\
Cocos nucifera & $80,00 \mathrm{~b}$ \\
Piper retrofractum Vahl. & $58,00 \mathrm{~cd}$ \\
Strychnos ligustrina & $50,00 \mathrm{~cd}$ \\
Anacardium occidentale L. & $100,0 \mathrm{a}$ \\
Molinga oleifera & $52,00 \mathrm{~cd}$ \\
Casia fistula. L. & $60,00 \mathrm{bed}$ \\
Thevetia perviana L. & $64,00 \mathrm{be}$ \\
Amorphophalluss variabilis & $52,00 \mathrm{~cd}$ \\
Annona squamosa L. & $46,00 \mathrm{cde}$ \\
Acassia spp. & $62,00 \mathrm{be}$ \\
Mucuna pruriensvar utilis & $54,00 \mathrm{~cd}$ \\
Vitex trivolia & $58,00 \mathrm{~cd}$ \\
Morinda citofilia & $56,00 \mathrm{~cd}$ \\
Astonia scholaris & $44,00 \mathrm{cde}$ \\
Methanol & $38,00 \mathrm{cde}$ \\
Aquades & $26,00 \mathrm{e}$ \\
\hline
\end{tabular}

Keterangan :Angka-angka yang diikuti oleh hurufyang sama dalam kolom yang sama, berarti berbeda tidak nyata pada uji Duncan 5\%. 
Tabel 3. Rerata persentase kunjungan, aktivitas makan dan kematian L. sativae karena ativitas repellen, antifidan dan racun perut dari setiap ekstrak tanaman

\begin{tabular}{lccc}
\hline \multicolumn{1}{c}{ Perlakuan } & $\begin{array}{c}\text { Kunjungan imago } \\
(\%)\end{array}$ & $\begin{array}{c}\text { Aktivitas makan imago } \\
(\%)\end{array}$ & $\begin{array}{c}\text { Kematian imago } \\
(\%)\end{array}$ \\
\hline Annona muricata L. & $80,24 \mathrm{~b}$ & $71.86 \mathrm{c}$ & $8,00 \mathrm{~cd}$ \\
Cocos nucifera & $42,56 \mathrm{de}$ & $35,06 \mathrm{ef}$ & $24,00 \mathrm{ab}$ \\
Piper retrofractum Vahl. & $19,57 \mathrm{e}$ & $22,99 \mathrm{f}$ & $28,00 \mathrm{ab}$ \\
Stryclinos ligustrina & $70,75 \mathrm{be}$ & $40,37 \mathrm{def}$ & $8,00 \mathrm{~cd}$ \\
Anacardium occidentale L. & $0,00 \mathrm{f}$ & $0,00 \mathrm{~g}$ & $36,70 \mathrm{a}$ \\
Molinga oleifera & $88,31 \mathrm{~b}$ & $58,78 \mathrm{~cd}$ & $8,00 \mathrm{~cd}$ \\
Casia fistula L. & $69,26 \mathrm{bed}$ & $42,75 \mathrm{def}$ & $8,00 \mathrm{~cd}$ \\
Tlievetia perviana L. & $48,31 \mathrm{cde}$ & $48,07 \mathrm{de}$ & $16,00 \mathrm{be}$ \\
Amorpliophalluss variabilis & $63,88 \mathrm{bed}$ & $58,43 \mathrm{cde}$ & $8,00 \mathrm{~cd}$ \\
Annona squainosa L. & $79,74 \mathrm{be}$ & $62,12 \mathrm{~cd}$ & $8,00 \mathrm{~cd}$ \\
Acassia spp. & $75,58 \mathrm{be}$ & $59,04 \mathrm{~cd}$ & $16,00 \mathrm{be}$ \\
Mucuna pruriensvar utilis & $64,07 \mathrm{bed}$ & $69,84 \mathrm{be}$ & $8,00 \mathrm{~cd}$ \\
Vitex trivolia $(13)$ & $81,80 \mathrm{~b}$ & $62,83 \mathrm{~cd}$ & $8,00 \mathrm{~cd}$ \\
Morinda citofilia & $73,33 \mathrm{bed}$ & $68,92 \mathrm{c}$ & $8,00 \mathrm{~cd}$ \\
Astonia scholaris & $62,51 \mathrm{bed}$ & $50,99 \mathrm{cde}$ & $0,00 \mathrm{~d}$ \\
Methanol & $88,75 \mathrm{~b}$ & $87,37 \mathrm{~b}$ & $0,00 \mathrm{~d}$ \\
Aquades & $100,0 \mathrm{a}$ & $100,0 \mathrm{a}$ & $0,00 \mathrm{~d}$ \\
\hline
\end{tabular}

Keterangan :

Angka-angka yang diikuti oleh huruf yang sama dalam kolom yang sama, berarti berbeda tidak nyata pada uji Duncan 5\%. Uji aktivitas repelan, racun perut dan antifeedan dilakukan secara terpisah

Ekstrak 15 tanaman (Tabel 1.) yang digunakan dalam percobaan ini menunjukkan aktivitas insektisida yang berbeda terhadap $L$. sativae (Tabel 2. dan Tabel 3.)- Menurut Kardinan (2001), secara evolusi tanaman telah mengembangkan senyawa kimia dengan fungsi tertentu sebagai alat untuk mempertahankan diri dari pengganggunya. Suprapta (2001), menjelaskan bahvva perbedaan senyawa aktif, si fat kimia dan konsentrasi yang terkandung dalam ekstrak tanaman merupakan penentu perbedaan aktivitas insektisida.

Ekstrak kulit biji tanaman A. occidentale L. pada pengujian aktivitas insektisida racun kontak menunjukkan rata-rata persentase kematian imago L. sativae tertinggi, yang berbeda sangat nyata dengan kontrol dan perlakuan ekstrak tanaman lainnya (Tabel 2.), namun juga menyebabkan persentase kerusakan daun yang tinggi dan rusaknya daun secara menyeluruh mengindikasikan sifat toksit dari minyak laka (CNSL) yang terkandung dalam ekstrak kulit biji tanaman A. occidentale L. sangat kuat. Diduga kerusakan daun juga disebabkan dosis 0,3 ml / tanaman yang digunakan masih terlalu banyak. Menurut Djojosumarto (2000), untuk mengurangi pengaruh yang ditimbulkan dan memaksimalkan fungsi bahan aktif murni pestisida yang bersifat sangat toksit maka bahan aktif perlu diformulasi terlebih dahulu dengan cara dicampur bahan-bahan pembantu sperti solven (bahan pelarut), emulsifter (bahan pembuat emulsi), diluent (bahan pembasah atau pengencer), carrier (bahan pembawa) dan bahan perekat.

Ekstrak buah tanaman $P$. retrofractum Vahl. pada uji aktivitas insektisida repellen, antifidan menunjukkan rata-rata kunjungan dan aktivitas makan terendah dengan rata-rata persentase kematian imago tertinggi pada uji aktivitas racun perut (Tabel 3.) diduga karena mengandung zat pedas piperine dan minyak atsiri. Rukmana (2003), menjelaskan bahwa dalam ekstrak buah tanaman Piper retrofractum Vahl. terkandung zat pedas piperine yang memiliki daya menidurkan yang kuat dan minyak atsiri yang memiliki aroma ٪ tidak sedap tetapi bersifat antiseptik.

\section{SIMPULAN}

Dari percobaan ini dapat dibuat simpulan sebagai berikut : Masing-masing ekstrak tanaman yang digunakan dalam percobaan ini mempunyai aktivitas insektisida yang berbeda terhadap $L$. sativae. Ekstrak kulit biji tanaman A. occidentale L. dan ekstrak buah tanaman Piper retrofractum Vahl. menunjukkan kemampuan aktivitas insektisida paling tinggi terhadap L. sativae

\section{UCAPAN TERIMA KASIH}

Pada kesempatan yang baik ini penulis ingin mengucapkan terima kasih yang tak 
terhingga kepada semua pihak yang telah membantu penulis terutama kepada yang terhormat Prof. I Wayan Supartha dan Bapak IG.M.Oka Nurjaya.

\section{DAFTAR PUSTAKA}

Cardona, C, Karel, A.K. 1990. Insect and orther invertebrate pest of beans. In S. R Sing. John Wiley and Sons Ltd. Insect Pest of food Legumes. J. Biocontrol News and Information 28: 157-191.

Djojosumarto, P. 2000. Teknik Aplikasi Pestisida Pertanian. Cetakan Pertama. Penerbit Kanisius. J1. Cempaka 9, Deresan, Yoyakarta.

Harwanto, D. Hindayana, N. Muryana., Rauf, A. 2001 Lalat predator Coenosia liumilis Meigen. (Diptera : Muscidae) pada pertanaman kentang: Pola Aktifitas harian, pemangsaan dan Pengaruh Aplikasi Insektisida. Jurnal Entomologi Indonesia. Perhimpunan Entomologi Indonesia.Jl Cimanggu kecil. Vol. 1, No. 1, September 2004. hal $1-8$.

Kardinan, A. 2001. Pestisida Nabati Ranutan dan Aplikasi. Cetakan ketiga. PT. Penebar Swadaya. Jakarta .

Mingkenberg, O.P.J.M., Van Lenteren. J.C. 1986. The Leafminers Lihomyza trifolii and L. bryoinae (Diptera: Agromyzidae), Their Parasites and Their Host Plants : A review. Agriculture Wageningen: University of Wageningen. 86(2): 1-50.
Prijono, D. 1988. Pengujian Insektisida penuntun praktikum. Jurusan Hama dan Penyakit Tumbuhan Fak. Pertanian IPB. Bogor.

Raman, K. V. 1988. Integrated insect pest management for potates in developing Countries. J.CIP Circular. Int. Potato Cent. (CIP).Lima, Peru. 16 (1) : 1-8

Rauf, A., Shepard, B.M., Johnson, M.W. 2000. Leafminers in Vegetables, Ornamental Plant and Weed in Indonesia: Surveys of Host Crops, Species Composition and Parasitoid. Int. J. Pest Manag. 40 (0) : 1 - 9.

Rukmana, H.R. 2003. Potensi dan Kasiat Cabai Jawa. Cetakan Pertama. Penerbit Kanisius. Jl.Cempaka 9, Deresan, Yoyakarta.

Steel, R.G., Torrie, J.H. 1980. Prinsip dan Prosed it r Statistika; Suatu Pendekatan Biometrika. Cetakan kedua. PT. Gramedia Pustaka Utama. Jakarta.

Supartha, I W. 1998. Bionomi Liriomyza huidobrensis (Blanchard) (Diptera : Agromyzidae) pada Tanaman Kentang. Disertasi. PPs. IPB. Bogor.

Suprapta, D.N. 2001. Meninjan Kembali Kebijakan Penggunaan Pestisida pada Lalian Pertanian, Pertanian Masa Depart; Kembali ke Pupuk Nabati. Yayasan Manikaya. Kauci.

Webb, R.E., Hinebaugh, M.A., Lindquist, R.K., Jacobson, M. 1983. Evaluation of aquaeous solution of neem seed extract against Liriomyza sativae and L. triffolii (Diptera: Agromyzidae). J. Econ. Entomol. 76: 357-362. 